\title{
Impact of Immigration on Native and Ethnic Consumer Identity via Body Image
}

\author{
Anurag G. Hingorani ${ }^{1}$, Lynne Freeman ${ }^{1} \&$ Michelle Agudera ${ }^{1}$ \\ ${ }^{1}$ Marketing Discipline Group, University of Technology Sydney, Broadway, Australia \\ Correspondence: Anurag G. Hingorani, Marketing Discipline Group, University of Technology Sydney, P. O. Box \\ 123, Broadway, NSW, Australia. Tel: 61-2-9514-3543. E-mail: Anurag.Hingorani@uts.edu.au
}

Received: November 8, 2016

Accepted: January 7, 2017 Online Published: January 16, 2017

doi:10.5539/ijms.v9n1p27

URL: http://dx.doi.org/10.5539/ijms.v9n1p27

\begin{abstract}
This research focuses on consumer identity of two under-researched but growing immigrant communities in Australia via the lens of the body image construct. Consistent with an emerging stream of research, body image is viewed as a part of identity. Given the variety of goods and services that have an impact on consumers' perceptions of their body, and because consumers use products to create and convey desired identities, body image is also viewed as a part of consumer identity. Considering literature on identity, body image, and acculturation, exploratory research was undertaken to determine the impact of immigration on the identities of both immigrants and natives. Specifically, focus groups were conducted on two generations of Filipino- and Indian-Australian women as well as Anglo-Australian women. It was found that second generation immigrants have dual consumer identities where they balance the values, attitudes and lifestyles of both their home (i.e., native or heritage) and host cultures whereas first generation immigrants tend to retain their native consumer identity even if they appear to adopt values, attitudes, and lifestyles of the host culture. The impact of immigrants on consumer identities of native residents who are typically in the majority (i.e., the Anglo group) was not evident. Theoretical and practical implications including recommendations for marketing practitioners are then discussed followed by suggestions for future research.
\end{abstract}

Keywords: body image, consumer identity, culture, immigration, social identity

\section{Introduction}

Whilst in consumer research, body image is not usually viewed as part of the identity domain (Dittmar, 2008), there is support to locate it there (Dittmar, 2008; Schouten, 1991; Venkatesh et al., 2010). Previous research identified body image as the subjective concept that a person holds of their body as part of their self-representation (Halliwell \& Dittmar, 2006) or self-concept (Schouten, 1991). Also, Venkatesh et al. (2010), connect body image to identity formation that is associated with a person's reception or interpretation of fashionable adornments such as clothing.

The identity of many women and girls has centred on issues such as appearance, beauty, and the perfect body (Dittmar, 2008). These issues are reflected in advertising and other imagery aimed at this audience who often feel pressured to make decisions about what products to consume (eat, drink, wear, etc.) in order to not only achieve and maintain but also communicate their desired identity, or what is viewed as being the desirable ideal, within their reference group or subculture. The issue of body image is not limited to women. Increasingly, men are feeling the pressure to look a certain way via exposure to image portrayals in social media. However, the focus of this research is women who, as found in a recent Dove Global Study, hate their body more than ever before with image issues reaching a "critical level" globally (Brown, 2016). Despite the abundant research on this demographic, including on native and immigrant women, body image issues of Indian- and FilipinoAustralian women is scant, at best. These two immigrant groups in Australia are under-researched yet growing in population. This study attempts to fill this research gap.

Although the beauty and clothing industries, for example, influence women's identity by portraying what is considered to be ideal, women's cultural heritage as well as exposure to values, attitudes and ideals of a different culture also have an impact (Furnham \& Alibhai, 1983). Hence, immigrant women who are potentially exposed to ideals of the host culture in which they reside are being investigated along with native (non-indigenous) women. 
Given the variety of goods and services that have an impact on consumers' perceptions of their body, and because consumers use products to create and convey desired identities (Belk, 1988), this research also views body image as a part of consumer identity. Studying the identity of immigrants via the lens of body image is important because they are growing in number and as consumers provide market potential for marketers of body-focused goods and services. Thus, the purpose of this research is to explore the impact of immigration on native and ethnic consumers' identity, where consumer identity is examined through the lens of the body image construct. In so doing, it addresses a gap in the identity literature that has examined ethnic identity of immigrants but not particularly investigated body image as a part of their identity.

Exploratory research via focus groups is conducted on the under-researched and growing immigrant groups in multicultural Australia, namely, Filipino- and Indian- Australians (Filipino- 120,533; Indian- 147,101; ABS, 2006 Census) (Filipino- 225,100; Indian- 397,200; ABS, 2013-2014), and specifically, older and younger generations of women. Implications and suggestions for future research are then discussed.

\section{Background}

\subsection{Identity and Body Image}

Identity can be defined as the subjective concept (or representation) which a person holds of himself or herself (Vignoles et al., 2006). It is not a static construct given that individuals can hold different identities in different contexts and at different points in time. In this sense, identity is concerned with the multifaceted and dynamic self (Hogg et al., 1995). For example, ethnic consumers who migrate to another country could form different identities as a result of their acculturation experience, i.e., the process of change in their values, attitudes, and societal standards when they move to, and are in continuous contact with, another culture (Berry, 1990). This is consistent with Becker (2004, p. 535) who suggests that identity "is "co-constructed" by the local social world in such a way that individuals draw heavily on cultural resources and symbols to construct, understand, and represent who they are (McKinley, 1997)". She suggests that "self-identity" in the Western world is created as a process of competitively positioning oneself via manipulation of cultural symbols such as by displaying consumption of material goods or decking the body in culturally salient ways. This could then be extended to body shape and size as well, which make up one's body image.

An individual could also hold multiple identities within a culture such as an identity at home, at work, with peers, and with family, to name a few. This is in line with both identity theory (e.g., Stryker, 1968) and social identity theory (e.g., Tajfel \& Turner, 1979; in Hogg et al., 1995) because they not only address the social nature of self as formed by society and avoid perspectives that treat self as independent of society but also view the self as differentiated into multiple identities that reside in bounded practices (e.g., norms, roles) (Hogg et al., 1995).

As aforementioned, a part of identity is body image although it has not been traditionally viewed as such. However, Belk (1988) alludes to this when suggesting that those who have altered their body via plastic surgery for example, are likely to view the affected body parts as being a part of their self. Besides being viewed as a part of identity, body image can be viewed as a part of consumer identity given the varied consumption contexts with which it is associated, including but not limited to goods and services that are body-focused such as those in the diet and clothing industries.

Body image is a multidimensional construct characterized by perceptions of, and attitudes toward, the body (Cash \& Brown, 1989). Due to the social influences on body image (Tiggemann \& Polivy, 2010), or put differently, because body image is socially constructed, it must be studied within its cultural context Grogan (2008). [For a detailed account of the effects of cultural influences on body image, refer to Grogan (2008)].

Given that body image is a part of one's self-representation (Dittmar, 2005) as well as an internal representation of one's own outer appearance (Thompson et al., 1999), it can be viewed as a part of identity. Moreover, body image can be linked to consumer identities such as: "I am an apple shape and can only wear certain clothes" or "I am body confident and not worried about what I eat". This is because in some consumption categories (e.g., diet, apparel, cosmetic surgery), there is at least an implicit, if not, explicit connection to the body, and hence one's body image. Relatedly, Schouten (1991) notes that when consumers' lives are in flux or transition following major life events including relocation, plastic surgery is a means of reintegrating the self-concept. This supports the view that body image issues are linked to one's sense of self or identity and suggests that consumer identity and body image can be viewed as being associated with each other.

\subsection{Immigration and Its Impact on the Identity of Migrants}

\subsubsection{Culture, Identity, and Body Image}

As aforementioned, issues of appearance, including those related to the body are central to the identity of many 
women and girls (Dittmar, 2008) and are revealed in advertising as well as media. According to Groesz et al. (2002), media communicate our culture's standards for thinness. However, "culture shapes our bodies, thoughts, feelings, desires, and values" (Venkatesh et al., 2010, p. 465). Culture plays a role in women's internalization of mainstream ideals for appearance (Henrickson, 2006) and is likely to play a role in understanding body experiences in ethnic women (Henrickson, 2006). In other words, immigration, and thus, moving to, and experiencing another culture, has a potential role to play in the adoption of these ideals by ethnic groups who are born overseas and resettle in a foreign (i.e., host or non-native or receiving society's) culture.

\subsubsection{Ethnicity/Ethnic Identity and Body Image}

Ethnic identity has been defined as "a dynamic, multidimensional construct that refers to one's identity or sense of self as a member of an ethnic group" (Phinney, 2003, p. 63).

Extensive research has been conducted in the area of ethnicity and body image, ranging from the effects of exposure to Western media (McCabe et al., 2005; Pompper \& Koenig, 2004), to the impact of sociocultural influences (Abrams \& Stormer, 2002), to comparative studies of general body dissatisfaction across cultures (Sheffield et al., 2005; Yates et al., 2004). Studies have found that many cultures value body image in quite distinct and contrasting ways. It has been found that many non-Western cultures value larger body shapes and sizes in comparison to the Western slim ideal (e.g., Farrales \& Chapman, 1999).

Yates et al. (2004) suggested that combining various ethnic groups under a single category such as an "Asian" category conceals important group difference. Therefore, this research aims to explore one Asian culture, namely, the Filipino culture, and another culture that is sometimes considered Asian, the Indian culture.

\subsubsection{Acculturation and Body Image}

Acculturation is the process of change an individual experiences when they are in continuous contact with another culture (Berry, 1990). Values, attitudes and society standards are adopted within this process, impacting upon the individual's development of ethnic identity.

Abrams et al. (1993) suggest that ethnic women who identified less with their heritage or native culture and more with the host culture, i.e., those who had higher levels of acculturation, had significantly greater body image issues as reflected in their controlled eating habits and greater levels of body dissatisfaction, for instance. Relatedly, in an Australian study, Tranter \& Hanson (2015) found that people born overseas are more than twice as likely to have had cosmetic surgery as Australian-born respondents.

Past research that has investigated the relationship between acculturation and body image has largely been quantitative (Ball \& Kenardy, 2002). Generational status is a common proxy variable utilised in quantitative acculturation research studies. It is employed on the basis that later generations experience acculturation at a much faster rate, whilst the first generation tend to maintain and hold on to their ethnic values and attitudes, keenly. First-generation immigrants are those born overseas, second-generation immigrants are those who were born in the host country but their parents were born overseas and third or greater generation immigrants are those who were born in the host country along with their parents (Valentine, 2001). In order to gain a deeper understanding of the acculturation process, generational status is employed in this research in a qualitative manner. In so doing, it has enabled the exploration of how first and second generation immigrants have dealt with the acculturation process and the extent to which the adoption of Australian attitudes and values has affected the development of their body image, i.e., consumer identity. Therefore, the Filipino- and Indian-Australian informants in this research study comprised of both first- and second-generation immigrants.

2.3 Immigration and Its Impact on the Identity of Natives (i.e., those who are typically in the majority in the receiving society)

The process of change that an Anglo-Australian has experienced due to the influx of migrants and the new multicultural society they now find themselves living in, could be viewed as "domestic" acculturation. Berry (1990) defines acculturation as the process of change an individual experiences when they are in continuous contact with another culture. Values, attitudes and society standards are adopted within this process, impacting upon the individual's development of ethnic identity. This Anglo-Australian acculturation experience has been termed "domestic acculturation" as they too, as natives or locals, might have had to adopt new values, attitudes and societal standards, which could then impact their view of their "Australian" identity. Thus, an Anglo-Australian adopting practices of some immigrant groups such as yoga and vegetarianism could hold different consumer identities as a result.

The foregoing background to the study of immigration's impact on consumer identity has pointed to the need to consider not only an under-researched and growing group of immigrants but also an under-researched aspect of 
identity, namely, body image. The next section describes the methodology used to explore the impact of immigration on the identities of immigrants, as well as natives who could potentially be affected by immigration, via the lens of body image.

\section{Methodology}

The challenge of capturing the dynamic and multi-dimensional nature of the constructs of consumer identity, acculturation, self and body image, determined the adoption of a qualitative focus group study (Creswell \& Miller, 2000). Additionally, it was important to ensure that, as a group, similarities and differences were revealed. This is because even though the informants had specific individual experiences, issues, and perspectives that were generally represented and were relevant for, their cultural group as a whole, had to be established.

\subsection{Sample}

Eight focus groups were conducted. Groups were segregated in terms of both culture and generation and comprised of Older Filipino, Older Indian, Younger Filipino, or Younger Indian Australians, and there were two groups each of the older and younger Anglo Australians. The total sample size was 36 .

The population from which the focus group participants were drawn consisted of two generations of Australian females with Anglo, Filipino, or Indian heritages who either had or were studying for a university degree. Whilst all of the participants were Australian citizens, the older, non-Anglo generations had to be born and educated in the Philippines or India, whereas, all the younger generations had to be born in Australia. As aforementioned, immigrants from the Philippines and India were selected because they are under-researched yet growing immigrant groups.

In this qualitative research, "generational status" was employed to deeply explore the acculturation experience of immigrants and its impact on their consumer- and self-identity. Therefore, one of the Filipino-Australian focus groups comprised of first-generation immigrants, and the other, comprised of second-generation immigrants. The same was true of the Indian-Australian focus groups.

To allow for the possibility that observed differences may be due to other external, non-cultural influences, all the female participants in the younger focus groups were aged between 20 and 25 years approximately to ensure they fit Generation Y characteristics and all the female participants in the older groups were aged between 43 and 55 years approximately to ensure they held the demographic characteristics of the Baby Boomer generation. This enabled control for a cohort or generational effect. The definition of a cohort as used in this research is the generational difference caused by the socio-cultural variables unique to their time in which the different generations were raised, i.e., a mother and daughter would have been exposed to different image ideals during their formative years (Forbes et al., 2005). Moreover, it was a requirement for the older Filipino and older Indian group members to have been born, and spent their formative years in the Philippines, and India, respectively. This was a criterion to ensure that they had thorough exposure to their native culture before migrating to Australia. In addition, all the participants were required to be either currently attending university or university educated, to ensure that education was not a variable that could have affected results. Finally, in order to prevent the study of body image perceptions from getting distorted by the religious differences (e.g., between Indian Hindus and Indian Muslims) and geographic dispersion (indicated by Fiji Indians and Malay Indians, for example) of the Indian diaspora, the older Indian group only consisted of Hindus (pre- and post-marriage) from India. The younger Indian group also consisted of Hindus.

It should be noted that the three cultures examined in this research can be characterised in terms of Hofstede's (1980) "Individualism" dimension (Oyserman et al., 2002) which is related to the concept of identity.

\subsection{Focus Group Data Collection and Analysis}

To facilitate focus group research, a discussion guide was utilised which primarily consisted of open-ended questions and various stimulus materials (advertisements and other images). A flexible approach to moderating the focus groups was taken, as none of the questions were "fixed" but rather utilised as a guide to ensure that all the major themes were covered throughout the duration of the focus groups. Focus groups ran for almost two hours, and were audio visually recorded. Recordings were transcribed, annotated and subsequently analysed. The analysis was both intra- and inter-group allowing reflection and interpretation of the key subsets in the data as well as the data set as a whole (Spiggle, 1994).

\section{Findings}

The examples of comments and observations from the focus groups that are provided below reflect the impact of immigration on identity and body image which, as earlier discussed, are linked to consumer identity. It should be 
noted that during the focus groups, some informants concurred with other informants' viewpoints either verbally or non-verbally (via a nod of the head, for instance) and this is not always specified below.

\subsection{Younger Filipino-Australians (YFA)}

Overall, the YFAs believed that their ethnic identity was Australian and saw their Filipino heritage as an "added bonus". They felt that they held the same Australian values and attitudes, and are experiencing the same Australian lifestyle as an Anglo-Australian but just had an "added" culture on top. Nevertheless, it was observed that many of the participants found it difficult to grapple with the discrepancy between their ethnic identity (of being and feeling Australian) and their ethnic appearance (looking Filipino). This discrepancy appeared to affect their body image, personal identities and their sense of self in their everyday lives.

When talking about body image, YFAs used their peers as a standard for comparison, which affirms the social identity theory. When questioned as to whether or not they were influenced by their peers, one of the YFAs responded:

"Sometimes I am. Like I'm the fattest out of you guys and I'm always like, oh damn, I've got to lose weight, got to lose it."

All YFAs placed particular importance on longer legs and generally being taller in stature. They found this physical trait to be attractive, and one which they used to compare themselves with Anglo-Australian females in their peer group. This was reflected in their description of their drawings of their desired body image:

YFA3: "I wanted her to be tall and ..."

YFA2: “...big boobed.”

Via projective techniques, it was revealed that YFAs would worry about their body image as an Anglo-Australian would, and would additionally worry about their education and familial responsibilities as a typical Filipino girl would.

Based on the foregoing it is evident that second generation Filipino women have dual identities which they balance in their day to day life. Their concerns about body image mirror those of their Australian peer group yet they are mindful of other aspects of the Filipino culture.

\subsection{Older Filipino-Australians (OFA)}

When questioned about their ethnic identity, they described themselves as "Filipino-Australians". However, it can be inferred from the tone of the discussion that being "Filipino" came from the heart, whereas being "Australian" was due to citizenship and circumstance - with neither having lesser value, rather pride was expressed for both cultures.

The OFAs were questioned as to whether they tried to maintain Filipino values and culture in Australia. A typical response was:

OFA1: "You try to maintain, but you still have to adopt you know, Australia..."

With respect to body image, OFAs commented that when they were growing up in the Philippines, they lived on the very basics and were not concerned with body image and appearance to the same extent as their daughters born in Australia. An Australian activity of going to the beach was shunned to not only avoid getting tanned but also avoid exposing the body. With respect to the latter, they do share some similarity with some Australian women who avoid the beach. However, polls reveal that this is because some of them are ashamed of their body (Weaver, 2007) unlike the Filipino informants who appear to have inhibitions due to their cultural background. They felt that a Filipino woman would be too self-conscious to wear a bikini unlike Australian women who were "braver" because they wore bikinis even if they were ageing, large in stature, or had wrinkles. A Filipino woman would instead cover her body with "loose clothing" and "long sleeve shirts". This is because, as mentioned by one of them, "We still have our inhibitions from back home."

Thus, it appears that first generation (older) Filipino immigrants tend to retain their native consumer identity even if they appear to adopt values, attitudes, and lifestyles of the host culture. With respect to body image issues, the older group hold on to the inhibitions (or values) of their homeland whereas the younger group strive for more Western ideals of being longer legged and bigger boobed.

\subsection{Younger Indian-Australians (YIA)}

With respect to their identity, YIAs relayed the following:

YIA1: “...for me, when I am in India, I feel like I'm Australian ... it's kinda like people can tell or people will be 
like, oh yeah, where are you from?, and then when I am in Australia, it's kinda like, oh where are you from?, and I'll be, like Sydney, and (they say), no, where are you really from? And it's like...oh, ok, India."

YIA1: "In terms of cultural values and stuff there is a bit of both....it's a bit of a mix."

With respect to body image related issues, which were often revealed in terms of clothing issues that involved exposing or covering up the body, YIAs revealed the following:

YIA1: “...if I'm buying a dress, I'm not sure if I should get my mum's opinion over my best friend's opinion....and I want her approval of it...she doesn't really comment on my actual body so I don't really know... whereas with my friends I'd be more worried with them."

YIA2: "I think it's a combination of friends and media (in terms of who influences my body image)."

YIA1: "I think it's very important...that male opinion. My dad is always complimenting me......and when he says something like, "where's the rest of that dress?" (all laugh) or "why don't you wear some pants under that?" then I'm kinda like, "oh my gosh", like what have I done......that kind of thing. At the same time, I'll blow him off about it, when I think it's a perfectly nice dress."

Based on the above, it is evident that second generation Indian women have dual identities which they balance in their daily life. Their issues surrounding body image reflect those of their Australian peer group given that they value the opinion of their friends and appear to be influenced by Australian media. This was revealed when describing the process of purchasing clothing. Yet they did not completely discount the opinion of their parents who had more traditional views of appropriate clothing. In so doing, they are trying to balance their dual identities of being Australian and Indian.

\subsection{Older Indian-Australians (OIA)}

With respect to their identity, an OIA commented:

OIA4: "We adopt the ways of life here and we adapt ourselves to the environment but somewhere deep down, I guess our past stays the way they are."

When talking about body image, the reference groups for OIAs were predominantly Australian and Hollywood celebrities rather than Bollywood, i.e., Indian movie celebrities. Examples of celebrities included: Megan Gale (Australian model), Michelle Pfeiffer, Meryl Streep, \& Salma Hayek. Interestingly, the reference groups comprised mainly of celebrities of European ancestry. It could be argued that due to immigration, OIAs are more attuned to imagery in Australia, which includes those of predominantly Australian or Hollywood celebrities. Indirectly, this suggests that immigration has played a role in their consideration of ideal body image ideals which may be reflected in the celebrities they have named. Further, with respect to body image, OIAs relayed the following:

OIA3: "What I feel is that, for us, we are not the priority, like we have not been brought up like that; it's always been our family, our parents, our brothers and our sisters (OIA1 nods in agreement). It's never about us. It's never about ...I need to look good, I need to look pretty; it's about what my family needs first, I come second. I never come first."

OIA5: "In Australia, we have adopted the Australian lifestyle in dress sense and things like that; I guess our focus is on our surroundings and our families than ourselves (OIA2 and OIA4 nod in agreement)."

OIA5: “....as Indian women we are not obsessed with our body shape (OIA2 and OIA4 nod in agreement)... I guess what I feel different with my colleagues is that we don't watch every little thing we eat in terms of calories, we are not bothered about what it will do to our tummy (laughs)."

Based on the foregoing, it appears that first generation (older) Indian immigrants tend to retain their native consumer identity, i.e., deep down they retain their past, even if they appear to adopt values, attitudes, and lifestyles of the host culture. With respect to body image issues, they appear to hold on to the values of their homeland by not focusing on themselves or their body but instead prioritising others in their family and other aspects of their life whereas the younger group, like their Western counterparts, tend to not focus so much on their family and their opinion especially when it comes to dressing their body and instead turn to their peers. The older generation appears to be more conservative in dress choices for the younger generation, who do not view clothing in the same traditional way as their parents. Thus, first generation (older) Indians are much less Australian compared to the second generation; for example, when it comes to conservative versus skimpy clothing and therefore body image presentation. This is in spite of the fact that the older generation believe that they themselves have adopted the Australian way of dressing. 
It should be noted that the older immigrant groups' ideals and values, i.e., identity could have changed during acculturation through imitation and identification rather than through exploration and construction (Schwartz et al., 2006). Given that collectivist (rather than individualist) cultural values are more compatible with identity formation through imitation and identification (Schwartz et al., 2006), we believe that the older Filipino- and Indian- Australians continue to exhibit their pre-existing collectivist cultural values by conforming to the ideals and values of their new home. So, on the surface it appears that they have adopted their host culture's values when in reality this may be due to the fact that they are retaining their home country's collectivist cultural values by imitating and identifying with the dominant culture of Anglo-Australians.

\subsection{Anglo-Australians (AA)}

One of the major themes to emerge from the focus groups was the issue of "domestic acculturation"; the process of change an Anglo-Australian has experienced due to the influx of migrants and the new multicultural society they now find themselves living in. Domestic Acculturation was particularly evident in the older rather than the younger Anglo-Australian focus group. The feelings of resentment, dislike, and offence were expressed in politically correct language towards ethnic immigrants who they perceived were "not making an effort" to integrate into Australian society and culture. OAA1 stated: "If someone's making a real effort to be a part of our culture, then they're sort of given a "fair go" (an Australian expression for giving someone an equal opportunity or chance); as long as they're trying."

The OAA group, in particular, demonstrated evidence of the concept of "domestic acculturation" due to the change they have experienced as a result of the influx of migrants and the new values, attitudes and society standards they have had to adopt; this has also influenced their perception of their identity of being "Australian" in the new multicultural society they find themselves living in. However, immigrant influence on their identity in terms of body image was not evident. This might be attributed to differences in physical appearance among the three cultural groups, with the Anglo natives therefore possibly discounting any influence on their identity by Filipino- and Indian- Australians especially with respect to body shape and size. Or it could be attributed to the fact that although Filipino- and Indian- Australians are increasingly represented in the Australian population, they are not yet a large enough or highly visible group to impact on the native Australian group's identity with respect to body image. Using the example of clothing, it is likely that the Anglo group saw no real value in adopting the Indian and Filipino ideals and in fact it is the latter two who are more likely to adopt the ideals of the Anglo group in order to assimilate with them in line with their collectivist cultural values.

In summary, it was found that second generation immigrants have dual consumer identities where they balance the values, attitudes and lifestyles of both their home (i.e., native or heritage) and host cultures whereas first generation immigrants tend to retain their native consumer identity even if they appear to adopt values, attitudes, and lifestyles of the host culture. The impact of immigrants on consumer identities of native residents who are typically in the majority (i.e., the Anglo group) was not evident.

\section{Theoretical and Practical Implications}

Viewing body image as part of the identity domain is not the norm, and this paper has contributed to this evolving stream of literature by considering the impact of immigration on consumer identities reflected in body image for under-researched, growing migrant groups in a multicultural society.

Understanding the impact of immigration on consumer identity, assessed in the context of body image issues, will enable local and global marketers to develop and offer relevant goods and services more effectively to consumers in multicultural countries around the world like Australia. For example, marketers of vehicles of consumer-based identities such as clothing (Thompson \& Hirschman, 1995) could offer specific products that enable consumers from different backgrounds to communicate or enhance their identities which might not necessarily be the same as their ethnicity. Moreover, these products could be promoted using imagery that does not alienate but resonates with them. Arguably, depending on their experiences with immigration, some new settlers will not be expecting or desirous of seeing their native stereotypes featured in advertising because, for example, their consumer identity is now that of a "typical" Australian. In this case, a "one size fits all (natives and immigrants)" imagery might be effective, and especially for marketers in terms of economy or efficiency. For other settlers, employing a "typical" or "one size fits all" imagery might not be effective especially if they are trying to balance their culture's traditional values with the mainstream values. This might be particularly true if this balancing act of some immigrants occurs alongside some natives who, while trying to maintain or reinforce their identity, might perhaps even adopt some of the values or lifestyles brought to their homeland by immigrant groups. Although discussed as an example, clothing marketers are not the only ones that need to understand and respond to the influence of immigration on consumption and shopping behaviours of immigrants 
and the receiving society (i.e., natives). Given that advertisements play important roles in shaping consumers' ideal self-images (Belk \& Pollay, 1985), advertisers across a broad spectrum of industries need to understand and reflect the cultural nuances of both immigrant and native groups in order to appeal to them in advertising. In the context of body image, this would mean reflecting different body shapes and sizes in ads that would resonate with rather than alienate both groups. An under-utilised method for marketing to immigrants in Australia is ethnic media and it would serve advertisers well to cater to specific cultural groups via placement of ads in such media even if they have acculturated into Australian society. This is because, as revealed by this research, some immigrants balance both host and home cultures and by reaching them via not only mainstream but also ethnic media, advertisers might be able to better engage them with their marketing messages. This is especially because the tone of these ethnic publications might resonate with them more strongly than mainstream Australian media, even if they are in the English language (Ross, 2012).

\section{Limitations and Future Research}

Body image is an issue that is potentially linked to values and attitudes of people from different religious groups. Although religion was a variable that was controlled within an immigrant group in this research, i.e., only Hindu Indian-Australians were researched, future research could, for example, consider Muslim Indian-Australians as well in order to explore the role of religion in influencing consumer identities including those tied to one's body image.

This research considered women; however, future research could consider consumer identities of men within the same ethnic groups of immigrants. Although our focus was on immigrants in Australia, it would be useful to understand if the same observations can be drawn from immigrants in other countries such as Canada, Sweden or Brazil where there is a strong localized body ideal. This would enable marketing and advertising practitioners in these countries to determine if it is necessary to feature a range of ethnicities in their advertising or if it would be perceived as being unnecessary or even unwelcome tokenism amongst both the native and immigrant populations. This research study facilitates the expansion of this area of research because the exploratory findings provide a basis for addressing the role of immigration on a consumer identity domain of body image on a larger scale with a wider variety of immigrant groups across other western countries besides Australia that have many and diverse immigrants.

\section{References}

Abrams, K. K., Allen, L. R., \& Gray, J. J. (1993). Disordered Eating Attitudes and Behaviors, Psychological Adjustment, and Ethnic Identity: A Comparison of Black and White Female College Students. International $\begin{array}{lllll}\text { Journal of } & \text { Eating } & \text { Disorders, } & \text { 14(1), }\end{array}$ https://doi.org/10.1002/1098-108X(199307)14:1<49::AID-EAT2260140107>3.0.CO;2-Z

Abrams, L. S., \& Stormer, C. C. (2002). Sociocultural Variations in the Body Image Perceptions of Urban Adolescent Females. Journal of Youth and Adolescence, 31(6), 443-450. https://doi.org/10.1023/A:1020211103936

ABS. (2006). 3412.0- Migration, Australia. Australian Bureau of Statistics, Canberra.

ABS. (2013-2014). 3412.0- Migration, Australia. Australian Bureau of Statistics, Canberra.

Ball, K., \& Kenardy, J. (2002). Body weight, body image, and eating behaviours: Relationships with ethnicity and acculturation in a community sample of young Australian women. Eating Behaviors, 3(3), 205-216. https://doi.org/10.1016/S1471-0153(02)00062-4

Becker, A. E. (2004). Television, Disordered Eating, And Young Women In Fiji: Negotiating Body Image And Identity During Rapid Social Change. Culture, Medicine and Psychiatry, 28(4), 533-559. https://doi.org/10.1007/s11013-004-1067-5

Belk, R. (1988). Possessions and the extended self. Journal of Consumer Research, 15(2), 139-168. https://doi.org/10.1086/209154

Belk, R., \& Pollay, R. (1985). Images of Ourselves: The Good Life in Twentieth Century Advertising. Journal of Consumer Research, 11(4), 887-897. https://doi.org/10.1086/209024

Berry, J. W. (1990). Psychology of Acculturation. In J. Berman (Ed.), Cross-Cultural Perspectives: Nebraska Symposium on Motivation 1989 (pp. 201-234). Lincoln, Nebraska: University of Nebraska Press.

Brown, V. (2016). Women's body confidence becomes a "critical issue” worldwide, Dove global study indicates. Retrieved from www.news.com.au 
Cash, T. F., \& Brown, T. (1989). Gender and Body Images: Stereotypes and Realities. Sex Roles, 21(5-6), 361-373. https://doi.org/10.1007/BF00289597

Creswell, J., \& Miller, D. (2000). Determining Validity in Qualitative Inquiry. Theory into Practice, 39(3), 124-130. https://doi.org/10.1207/s15430421tip3903_2

Dittmar, H. (2005). Introduction to the Special Issue: Body Image-Vulnerability factors and processes linking sociocultural pressures and body dissatisfaction. Journal of Social and Clinical Psychology, 24(8), 1081-1087. http://dx.doi.org/10.1521/jscp.2005.24.8.1081

Dittmar, H. (2008). Understanding the impact of consumer culture. In H. Dittmar (Ed.), Consumer Culture, Identity and Well-Being (pp. 1-23). New York: Psychology Press.

Farrales, L. L., \& Chapman, G. E. (1999). Filipino Women Living in Canada: Constructing Meanings of Body, Food, and Health. Health Care for Women International, 20(2), 179-194. http://dx.doi.org/10.1080/0739933992458722508

Forbes, G. B., Adams-Curtis, L., Jobe, R. L., White, K. B., Revak, J., Zivcic-Becirevic, I., \& Pokrajac-Bulian, A. (2005). Body Dissatisfaction in College Women and Their Mothers: Cohort Effects, Developmental Effects, and the Influences of Body Size, Sexism, and the Thin Body Ideal. Sex Roles, 53(3), 281-298. http://dx.doi.org/10.1007/s11199-005-5686-2

Furnham, A., \& Alibhai, N. (1983). Cross-cultural differences in the perception of female body shapes. Psychological Medicine, 13(4), 829-837. https://doi.org/10.1017/S0033291700051540

Groesz, L. M., Levine, M. P., \& Murnen, S. K. (2002). The effect of experimental presentation of thin media images on body satisfaction: A meta-analytic review. International Journal of Eating Disorders, 31(1), 1-16. https://doi.org/10.1002/eat.10005

Grogan S. (2008). Body Image: Understanding Body Dissatisfaction in Men, Women and Children. London: Routledge.

Halliwell, E., \& Dittmar, H. (2006). The role of appearance-related self-discrepancies for young adults' affect, body image, and emotional eating: A comparison of fixed-item and respondent-generated self-discrepancy measures. Personality and Social Psychology Bulletin, 32, 447-458. https://doi.org/10.1177/0146167205284005

Henrickson, H. (2006). Understanding Body Experiences and the Relationships among Ethnic Identity, Acculturation, And Internalization of the Thinness Ideal among Hispanic and Latina Women (unpublished doctoral dissertation). Kent State University, USA.

Hogg, M., Terry, D., \& White, K. (1995). A Tale of Two Theories: A Critical Comparison of Identity Theory with Social Identity Theory. Social Psychology Quarterly, 58(4), 255-269. https://doi.org/10.2307/2787127

McCabe, M. P., Ricciardelli, L. A., Mellor, D., \& Ball, K. (2005). Media Influences on Body Image and Disordered Eating Among Indigenous Adolescent Australians. Adolescence, 40(157), 115-127.

McKinley, E. G. (1997). Beverly Hills, 90210: Television, Gender, and Identity. Philadelphia, PA: University of Pennsylvania Press. https://doi.org/10.9783/9780812200751

Oyserman, D., Coon, H. M., \& Kemmelmeier, M. (2002). Rethinking Individualism and Collectivism: Evaluation of Theoretical Assumptions and Meta-Analyses. Psychological Bulletin, 128(1), 3-72. https://doi.org/10.1037/0033-2909.128.1.3

Phinney, J. S. (2003). Ethnic identity and acculturation. In M. Chun, P. B. Organista, \& G. Marin (Eds.), Acculturation: Advances in theory, measurement, and applied research (pp. 63-81). American Psychological Association, Washington D.C. http://dx.doi.org/10.1037/10472-006

Pompper, D., \& Koenig, J. (2004). Cross-Cultural-Generational Perceptions of Ideal Body Image: Hispanic Women and Magazine Standards. Journalism and Mass Communication Quarterly, 81(1), 89-107. https://doi.org/10.1177/107769900408100107

Ross, M. (2012). The Culture Club. B\&T, 28 September, 22-27.

Schouten, J. W. (1991). Selves in Transition: Symbolic Consumption in Personal Rites of Passage and Identity Reconstruction. Journal of Consumer Research, 17(4), 412-425. https://doi.org/10.1086/208567

Schwartz, S. J., Montgomery, M. J., \& Briones, E. (2006). The Role of Identity in Acculturation among Immigrant People: Theoretical Propositions, Empirical Questions, and Applied Recommendations. Human 
Development, 49, 1-30. http://dx.doi.org/10.1159/000090300

Sheffield, J. K., Tse, K. H., \& Sofronoff, K. (2005). A Comparison of Body-Image Dissatisfaction and Eating Disturbance among Australian and Hong Kong Women. European Eating Disorders Review, 13(2), 112-124. http://dx.doi.org/ 10.1002/erv.641

Spiggle, S. (1994). Analysis and Interpretation of Qualitative Data in Consumer Research. Journal of Consumer Research, 21(3), 491-503. http://dx.doi.org/10.1086/209413

Stryker, S. (1968). Identity Salience and Role Performance: The Relevance of Symbolic Interaction Theory for Family Research. Journal of Marriage and Family, 30(4), 558-564. http://dx.doi.org/ 10.2307/349494

Tajfel, H., \& Turner J. (1979). An Integrative Theory of Intergroup Conflict. In W.G. Austin \& S. Worchel (Eds.), The Social Psychology of Intergroup Relations (pp. 33-47). Brooks-Cole: Monterey.

Thompson, C. J., \& Hirschman, E. C. (1995). Understanding the Socialized Body: A Poststructuralist Analysis of Consumers' Self-conceptions, Body images, and Self-care practices. Journal of Consumer Research, 22(2), 139-153. https://doi.org/10.1086/209441

Thompson, J. K., Heinberg, L. J., Altabe, M., \& Tantleff-Dunn, S. (1999). Exacting Beauty: Theory, Assessment and Treatment of Body Image Disturbance. American Psychological Association, Washington. http://dx.doi.org/10.1037/10312-000

Tiggemann, M., \& Polivy, J. (2010). Upward and Downward: Social Comparison Processing of Thin Idealized

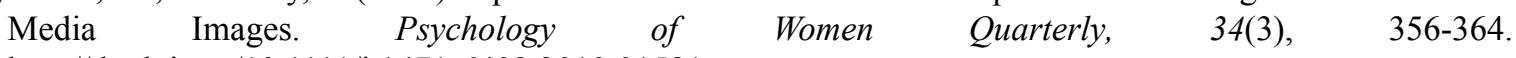
http://dx.doi.org/10.1111/j.1471-6402.2010.01581.x

Tranter, B., \& Hanson, D. (2015). The social bases of cosmetic surgery in Australia. Journal of Sociology, 51(2), 189-206. http://dx.doi.org/10.1177/1440783313487812

Valentine, S. (2001). Self-Esteem, Cultural Identity, and Generation Status as Determinants of Hispanic Acculturation. Hispanic Journal of Behavioral Sciences, 23(4), 459-468. https://doi.org/10.1177/0739986301234007

Venkatesh, A., Joy, A., Sherry Jr., J. F., \& Deschenes, J. (2010). The Aesthetics of Luxury Fashion, Body and

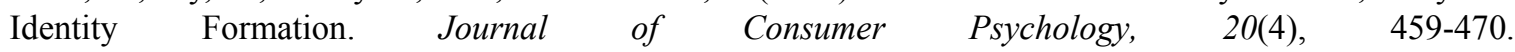
https://doi.org/10.1016/j.jcps.2010.06.011

Vignoles, V., Regalia, C., Manzi, C., Golledge, J., \& Scabini, E. (2006). Beyond Self-Esteem: Influence of Multiple Motives on Identity Construction. Journal of Personality and Social Psychology, 90(2), 308-333. https://doi.org/10.1037/0022-3514.90.2.308

Weaver, C. (2007). Real image problem-Poll reveals two-thirds of women ashamed of their bodies. The Sunday Telegraph, May 6, p. 11.

Yates, A., Edman, J., \& Aruguete, M. (2004). Ethnic Differences in BMI and Body/Self-Dissatisfaction among Whites, Asian Subgroups, Pacific Islanders, and African-Americans. Journal of Adolescent Health, 34(4), 300-307. https://doi.org/10.1016/S1054-139X(03)00305-7

\section{Copyrights}

Copyright for this article is retained by the author, with first publication rights granted to the journal.

This is an open-access article distributed under the terms and conditions of the Creative Commons Attribution license (http://creativecommons.org/licenses/by/4.0/). 